\title{
Application of Project Time Management Tools and Techniques to the Construction Industry in the Gaza Strip
}

Nabil El Sawalhi (United Nations Relief and Work Agency, Gaza, Palestine) and Adnan Enshassi (Civil Engineering Department, the Islamic University of Gaza, Palestine)

\begin{abstract}
The objective of this paper is to investigate the level of applying the project time management tools and techniques by public owners and construction contractors in the Gaza Strip. This study has been conducted by means of a survey questionnaire. Seventythree questionnaires were distributed to target construction contractors and twenty-five questionnaires to public owners. Sixty completed questionnaires from contractors and twenty-three questionnaires from public owners were received and analysed. The survey results indicated that contemporary project time management tools and techniques are not widely used among local contractors and owners. Lack of subcontractor's knowledge and awareness of the importance of project time management tools and techniques are still major obstacles toward the efficient utilisation of such tools. This study recommended that there is an urgent need to establish a professional industry body such as an Institute of Building to review and evaluate existing local project management practices. This professional body may be established by the government through the Ministry of Housing and Public Works or by the local university in cooperation with a similar international professional industry body. Current training effort should be tailored to encourage owners and contractors to use work breakdown structures, resource optimisation, and network scheduling.
\end{abstract}

Keywords: management tools, contractors, owners, time, Gaza Strip.

\section{INTRODUCTION}

The Gaza Strip, with an area of $365 \mathrm{~km} 2$ and a total population of 1.1 million, is located on the south eastern coast of the Mediterranean Sea. Toward the east and north the Gaza Strip is bordered by Israel, on the south it is bordered by Egypt and on the west by the Mediterranean Sea. Its length is about $45 \mathrm{~km}$ and the width is $6 \mathrm{~km}$ in the north with maximum width of $12 \mathrm{~km}$ in the south (FAFO Report, 1993). The Gaza Strip demographic growth rate is among the highest in the world (World Bank, 2001). The Palestinian economy may be characterised by its limited size. In 1999 , GDP accounted for approximately US $\$ 4.15$ billion and the GDP per capita reached approximately US $\$ 1,500$. The GNP per capita was higher, around US $\$ 1,800$, given the large inflow of remittances from Palestinian workers in Israel and international aid. By using GNP or GDP criteria, the West Bank and Gaza Strip is ranked within the group of lower middle income countries, while the demographic growth rate is among the highest in the world (World Bank, 2001).

The construction sector in Palestine had experienced a considerable growth following the aftermath of the 1967 war. In 1994, the construction sector represented $26 \%$ of the GDP (PECDAR, 1997). However, in 1998, it appears that the contribution of the construction sector to the GDP has been reduced to $11 \%$ (PCBS, 2000). By the fall of 1996, the construction sector was employing $13 \%$ of Palestinian workers (MAS, 2001).
Later, many projects were launched under the control of the Palestinian authority. It has been noticed that project management becomes all the more important in the construction industry of the Gaza Strip due to the increase in the number, size and complexity of the projects. The local practices indicate that a lot of failures have occurred in a considerable number of contracting companies during the last ten years, which makes it very important to investigate existing project management practices. The political, economic and cultural conditions in the Gaza Strip, in addition to the lack of planning and weak performance of both public owners and contractors, have left their marks on the project management industry. The unpredictable success or failure of major contracting companies, the long delays of important projects, and the low quality of some projects reflect an ambiguous picture on the practices used in project management (Enshassi, 1997).

This paper is intended to explore the project time management practices used by public owners and construction contractors in the Gaza Strip and to identify the major obstacles towards the efficient utilisation of those practices.

\section{BACKGROUND OF PROGRAMME MANAGEMENT TOOLS}

Abbasi and Al-Mharmah (2000), Hutchings and Christofferson (2000; 2001), Yang et al. 1997, Shash and Al-abdullatif (1993), White and Fortune (2002), and Kazi (2002) have examined various schedule management tools and techniques. They have selected and identified seven time management tools and techniques as the most popular tools among others. These tools include work breakdown structures, bar charts and linked bar charts, critical path method, resource levelling, schedule crashing and schedule updating, and have been adopted in this study.

Shash and Al-abdullatif (1993) have investigated planning, scheduling, and controlling (PSC) techniques in Saudi Arabia. They concluded that the bar chart is the most popular planning technique; the graphical program evaluation and review technique has never been used at all. Abbasi and Al-Mharmah (2000) has conducted their research in Jordan, which is quite similar to the Gaza Strip in terms of project features. Among numerous management tools and techniques, program evaluation and review technique (PERT), activity on arrow (AOA), activity on node (AON), bar chart, organisational breakdown structure (OBS), work breakdown structure (WBS), critical path method (CPM) and resource levelling have been investigated. Also the researchers asked about the obstacles towards the implementation of project management tools and techniques.

The researchers concluded that the most significant obstacle in implementing project management tools is the lack of knowledge of project management techniques. The gantt chart is the most widely used tool because of its simplicity and applicability in all phases. The use of networks is considerably low. Almost two-thirds of the investigated sample reveals that neither WBS nor OBS are utilised. Finally, the researchers concluded that the appropriate 
use of project management tools and concepts is one of the major factors affecting the economic performance so that more attention should be given to establish specifications and more focus should be given on training for employees.

\section{METHODOLOGY}

This study has been conducted by means of a survey questionnaire. Seventy-three questionnaires were distributed to selected construction contractors and twenty-five questionnaires to public owners in the Gaza Strip. Sixty completed questionnaires from contractors and twenty-three questionnaires from public owners were received and analysed. The total number of contractors in the Gaza Strip who have valid registration with the contractor's union (categorised under first, second and third category) are 90 enterprises. The 'first' class contractors are assigned to large projects while 'third' class contractors are assigned to small projects. For example, first level class contractors should have completed projects not less than 6 million US dollars during the last ten years. The main criteria for classification are related to company previous experience, capital, the value of executed projects, staffing and financial situation during the last ten years. The lists of contractors are published annually and the qualification of contractors is reviewed every two years by the National Committee for Contractors Classification.

The samples were selected randomly from each level of three contractor's categories. For analysing the data of an ordinal scale, an importance index (I) was used. The importance index was computed using the following equation.
$I=\sum_{i=1}^{n} \frac{a_{i} \times x_{i}}{n-1}$

Where: I = importance index; $\mathrm{a}_{i}=$ donstant expressing the weight of the $i$ th response, where $a_{i}=0,1,2,3$ respectively [if the first level of ranking, rate nonuse/no importance (Mezher and Tawil, 1998)]; $x_{i}=$ frequency of the $i$ th response given as a percentage of the total responses for each cause; $i=$ response category index where $\mathrm{i}=1,2,3,4, \ldots$.

The importance index (I) for all causes was calculated. The indexes were ranked for public owners and contractors. The group index is the average of factors in each group. The agreement between the rankings of any two parties was measured using the Spearman's rank correlation test which will be conducted using the SPSS statistical program.

\section{RESULTS AND DISCUSSION}

\section{Study population characteristics}

The characteristics of study population are outlined in Table 1. More than half of the public owner's organisations (57\%) were established before the existence of the Palestinian National Authorities (PNA), while more than three-quarters of the contracting companies (79\%) were established after 1994, following the establishment of PNA. This means that most contracting companies have limited construction experience which is likely to affect the level of use of project management tools

\begin{tabular}{|c|c|c|c|c|c|c|c|}
\hline \multicolumn{2}{|c|}{ Characteristics } & \multicolumn{2}{|c|}{ Owners } & \multirow[t]{2}{*}{ Total } & \multicolumn{2}{|c|}{ Contractors } & \multirow[t]{2}{*}{ Total } \\
\hline & & No. & $\%$ & & No. & $\%$ & \\
\hline \multirow[t]{3}{*}{ Year of establishment } & Before 1994 & 13 & 57 & \multirow[t]{3}{*}{23} & 12 & 21 & \multirow[t]{3}{*}{58} \\
\hline & $1994-1995$ & 6 & 26 & & 32 & 55 & \\
\hline & After 1995 & 4 & 18 & & 14 & 24 & \\
\hline \multirow[t]{4}{*}{ Field of work } & Building & 19 & 83 & \multirow[t]{4}{*}{23} & 59 & 98 & \multirow[t]{4}{*}{60} \\
\hline & Water \& Drainage & 16 & 70 & & 33 & 55 & \\
\hline & Roads & 16 & 70 & & 33 & 55 & \\
\hline & Others & 14 & 61 & & 7 & 12 & \\
\hline \multirow[t]{4}{*}{ Education (level of experience) } & Ph.D. & 4 & 18 & \multirow[t]{4}{*}{22} & 4 & 7 & \multirow[t]{4}{*}{60} \\
\hline & M.Sc. & 13 & 57 & & 12 & 20 & \\
\hline & B.Sc. & 23 & 100 & & 60 & 100 & \\
\hline & Diploma & 20 & 91 & & 57 & 95 & \\
\hline \multirow[t]{5}{*}{ Employees specialisation } & Civil & 21 & 100 & \multirow[t]{5}{*}{21} & 57 & 97 & \multirow[t]{5}{*}{59} \\
\hline & Architect & 14 & 67 & & 31 & 53 & \\
\hline & Electrical Engineering & 16 & 76 & & 20 & 34 & \\
\hline & Mechanical Engineering & 13 & 62 & & 18 & 31 & \\
\hline & Technician & 18 & 86 & & 49 & 83 & \\
\hline
\end{tabular}

The total number of respondents $=83,23$ owners and 60 contractors. Missing number was due to not answering some questions.

Table 1: Summary of the main characteristics of the study population 
and techniques (PMTT). Furthermore, the sudden increase in establishing new contracting companies after the arrival of PNA indicated that most of the new companies were very optimistic about getting more projects.

Nearly all contracting companies (98\%) and $83 \%$ of public owners are involved in building works, while close to $70 \%$ of the owners and $55 \%$ of contractors were working in water, drainage, and road fields. All owners and contractors were employing people who have B.Sc. degrees, while $18 \%$ of the owners and $7 \%$ of the contractors were employing employees who have Ph.D.'s. In addition, $57 \%$ of the owners and $20 \%$ of the contractors have employed persons who hold M.Sc. degrees.

As shown in Figure 1, very few owners $(8 \%)$ have less than
14 employees, while $29 \%$ of the contractors have less than 7 employees. Around half of the contractors $(52 \%)$ have $7-14$ employees. Almost all the owners $(91 \%)$ have more than 14 employees. Meanwhile only a small number of the contractors $(19 \%)$ have more than 14 employees. This means that the majority of the contractors are categorised as small-size companies, which will limit the volume and capacity of the work done by them. The small volume of projects, the seasonality of work and uneven work volume may explain the small size of the contracting firms. It was found that there is a very weak correlation between the number of employees of respondent organisations and the use of time management tools and techniques. This can be explained by the fact that organisations employ a small number of persons.

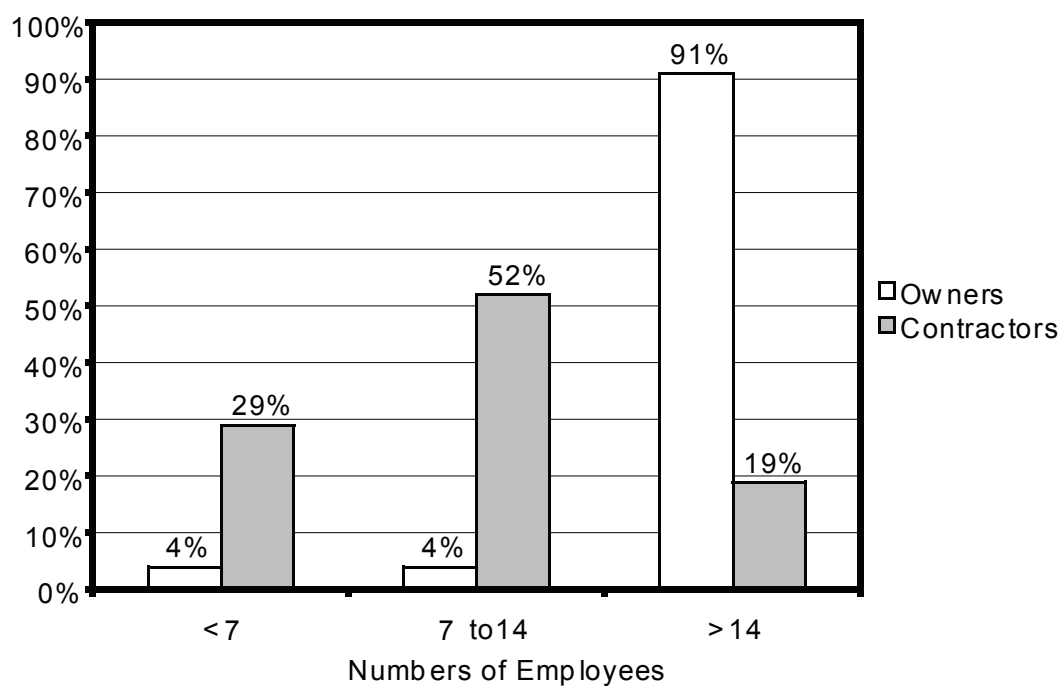

Figure 1: Distribution of respondents by number of employees

The study population comprises of 23 public owners (28\%) which represents $92 \%$ of the total public owner population, while the 60 respondent contractors represent $82.2 \%$ of the contractors sample size. Regarding the classification of each respondent contracting company, Figure 2 illustrates that $60 \%$ of the companies were grouped in the first class, $30 \%$ of them were grouped in the second class, while only $10 \%$ of the contracting companies were grouped in the third class. This distribution shows that the stratum of the first class contractors is very high when compared with other categories.

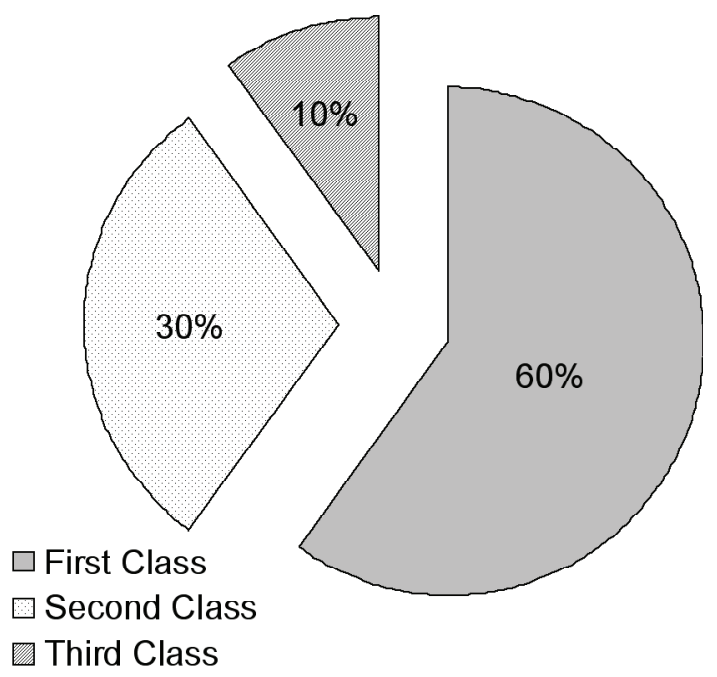

Figure 2: Distribution of respondent contractors by their classification 
Figure 3 shows the distribution of the respondents' positions, with $73 \%$ of respondents being either president, or vice president. The higher position of the respondents will give credible confidence in the quality of answers and also express the respondents' concern to deal seriously with this research. It was found that there is no significant difference in relation to the position of respondents and the use of PMTT. However, project managers have a higher concern about rating time management tools and techniques. This can be explained as project managers have a greater awareness and knowledge of these tools. Other reasons may be that project managers are the persons who are more qualified than others in implementing project management techniques.

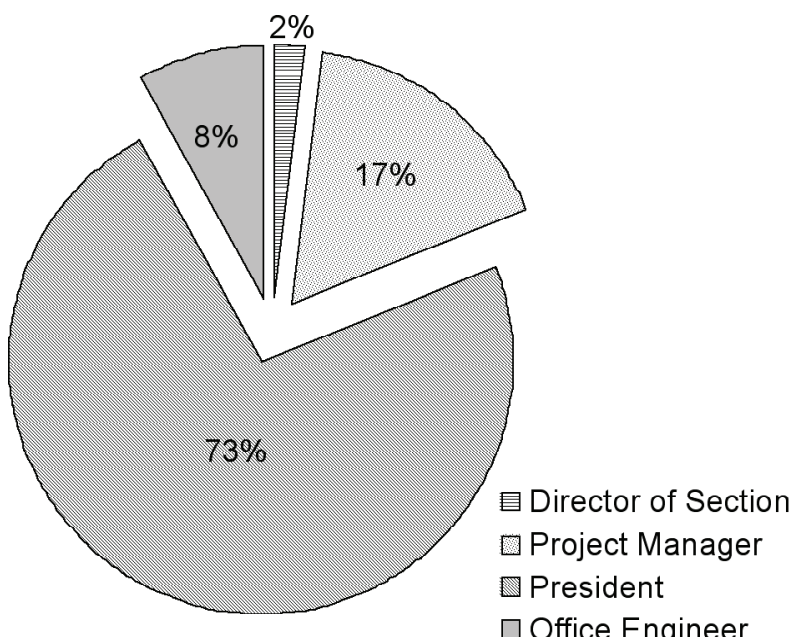

Figure 3: Distribution of respondent's position

\section{USE OF TIME MANAGEMENT TOOLS AND TECHNIQUES}

It is found that $44 \%$ of the study population (Table 2 ) has 'never' used WBS, while only $17 \%$ of the study population 'always' used WBS. The low use of WBS may be attributed to the unawareness of its importance and due to the lack of knowledge about its application. When asked about scheduling construction activities the respondents indicated that linked bar charts are used more frequently (frequently is used to indicate both the 'usually' and 'always' scale) than bar charts. That is, about two-thirds of participants (65\%) were 'frequently' using linked bar charts, while half of the respondents (51\%) were 'frequently' using bar charts.
Networks (AoA/AoN) were 'frequently' used by $4 \%$ of respondents. The result of this research is supported by the study conducted by Abbasi and Al-Mharmah (2000) and Yang et al. (1997). The study conducted by White and Fortune (2002) in the UK showed a higher use of WBS and network scheduling than other research studies. However, the Gaza Strip owners and contractors are the lowest in using networks among Jordan, Pudong and the UK. It is observed that network scheduling consumes more time in preparation than other methods of scheduling. Also, perhaps the size, the volume and complexity of projects in the Gaza Strip direct the planners to use simple tools rather than others. Furthermore, there is no tendency from owners or consultants to request network schedules.

\begin{tabular}{|c|c|c|c|c|c|c|}
\hline \multirow{2}{*}{\multicolumn{2}{|c|}{ Time management tools and techniques }} & \multicolumn{5}{|c|}{ Degree of usage } \\
\hline & & $\mathrm{N}$ & 0 & $U$ & $A$ & Total \\
\hline \multirow{2}{*}{ Work breakdown structure } & No. & 36 & 17 & 14 & 14 & \multirow{2}{*}{81} \\
\hline & $\%$ & 44 & 21 & 17 & 17 & \\
\hline \multirow{2}{*}{ Bar chart } & No. & 16 & 24 & 21 & 20 & \multirow{2}{*}{81} \\
\hline & $\%$ & 20 & 30 & 26 & 24 & \\
\hline \multirow{2}{*}{ Linked bar chart } & No. & 12 & 17 & 18 & 36 & \multirow{2}{*}{83} \\
\hline & $\%$ & 14 & 21 & 22 & 43 & \\
\hline \multirow{2}{*}{ Networks (AoA/AoN) } & No. & 73 & 6 & 0.0 & 3 & \multirow{2}{*}{82} \\
\hline & $\%$ & 89 & 7.3 & 0.0 & 3 & \\
\hline \multirow{2}{*}{ Updating time schedule } & No. & 4 & 19 & 29 & 31 & \multirow{2}{*}{83} \\
\hline & $\%$ & 5 & 23 & 35 & 37 & \\
\hline \multirow{2}{*}{ Crashing time schedule } & No. & 19 & 48 & 9 & 5 & \multirow{2}{*}{81} \\
\hline & $\%$ & 23 & 59 & 11 & 6 & \\
\hline \multirow{2}{*}{ Resource allocation and levelling } & No. & 32 & 31 & 10 & 9 & \multirow{2}{*}{82} \\
\hline & $\%$ & 39 & 38 & 12 & 11 & \\
\hline
\end{tabular}

( $N=$ never used,$O=$ occasionally, $U=$ usually, $A=$ always $)$

Table 2: Degree of using time management tools and techniques 
Also of interest was the fact that nearly three-quarters of the study population $(72 \%)$ was 'frequently' updating their time schedules. One of the main reasons for extensively using this tool is due to the prevailing situation in Gaza Strip. That is, the frequent delay of construction projects due to closures and shortage of materials forces organisations to frequently update their time schedules. In addition, the use of the computer in project scheduling makes updating an easy task.

On the other hand, only $17 \%$ of the study population was 'frequently' crashing the time schedule. Around half of the respondents (48\%) were 'occasionally' crashing the time schedule. Approximately ten percent of organisations were always using the resource allocation and levelling technique. The study population does not extensively use resource allocation and levelling. Only around a quarter of the study population was frequently using this tool. This result is similar to the study conducted by Abbasi and Al-Mharmah (2000) in Jordan. The argument is that the low use of the resource allocation tool results from extensive use of subcontractors. That is, the responsibility of resource allocation is transferred to them. Furthermore, resource allocation may consume considerable efforts and may need a wide range of data during the planning stage that is not dealt with seriously by whileGaza Strip organisations.

As shown in Table 3, updating time schedules is the most widely used tool by both parties. Linked bar charts are rated second while bar charts are third. It is clear that the least used tool is network scheduling.

\begin{tabular}{|l|c|c|c|c|}
\hline \multirow{2}{*}{\multicolumn{1}{c|}{ Tools \& Techniques }} & \multicolumn{2}{c|}{ Owners } & \multicolumn{2}{c|}{ Contractors } \\
\cline { 2 - 5 } & Index & Rank & Index & Rank \\
\hline Updating time schedule & 73 & 1 & 67 & 1 \\
\hline Linked bar chart & 65 & 2 & 64 & 2 \\
\hline Bar chart & 58 & 3 & 49 & 3 \\
\hline Work breakdown structure & 40 & 4 & 34 & 4 \\
\hline Resource allocation and leveling & 33 & 6 & 31 & 5 \\
\hline Crashing time schedule & 32 & 5 & 34 & 6 \\
\hline Network scheduling & 9 & 7 & 5 & 7 \\
\hline
\end{tabular}

Table 3: Ranking for using time management tools and techniques

The Spearman's rank correlation test for agreement on ranking time practices indicated that there is a very strong correlation between owners and contractors (rho $=0.964)$. That is, both parties are strongly agreed on the ranking of these factors. The t-test identified that the correlation is significant at the 0.01 level, which directs to reject the null hypothesis $\mathrm{HO}(r)=0$. Both owners and contractors generally agreed on the ranking of using time tools and techniques. Therefore, the level of using the time tools by both owners and contractors is generally equal. The equal use of time practices can be interpreted that there is a mutual concern between owners and contractors about using such practices. They may also have an equal knowledge about using these tools.
To find out the mean values of using PMTT for owners and contractors, the average scores for degree of using time tools have been calculated as shown in Table 4. A t-test was conducted to compare the mean value of using PMTT. Owners showed a slightly higher preference in using time tools than contractors. However, the t-test revealed no significant differences between both parties ( $\mathrm{Pv}$ $>0.05$ ). Moreover, one can say that the level of using time tools is generally far from satisfactory. The low level of using time practices (less than 60\%) may be linked to several factors. The first is the general low awareness and lack of knowledge about the use of such tools among the study sample. The second factor is the lack of experience of the study population in using time practices. The third factor is that the contract documents do not include requirements for an extensive use of time practices.

\begin{tabular}{|c|c|c|c|c|c|}
\hline \multicolumn{4}{|c|}{ Organisation } & \multirow{2}{*}{$t$} & \multirow{2}{*}{$\mathbf{P}_{\mathrm{v}}$} \\
\cline { 1 - 3 } \multicolumn{2}{|c|}{ Contractor } & \multicolumn{2}{|c|}{ Owner } & & \\
\cline { 1 - 3 } Mean & $\%$ & Mean & $\%$ & & \\
\hline 2.22 & 55.5 & 2.37 & 59.3 & -1.081 & 0.283 \\
\hline
\end{tabular}

* Statistically significant

Table 4: Mean values for groups of project management tools and techniques 
Considering the necessity of time practices, Figure 4 and Figure 5 illustrate the frequency of each time tool in this regard. About half of the contractors (48\%) believe that WBS is 'required' while $71 \%$ of the owners believe this. Close to two-thirds of the owners considered 'bar charts' and 'linked bar charts' as 'required' a majority of the contractors (92\%) and owners (89\%) considered networks to be 'optional'. Most of the owners and contractors considered updating time schedules to be 'required' while about two-thirds of the owners and contractors regarded schedule crashing to be 'optional'. The Chi square analysis demonstrates that there were no statistical significant differences between owners and contractors in evaluation of the above.

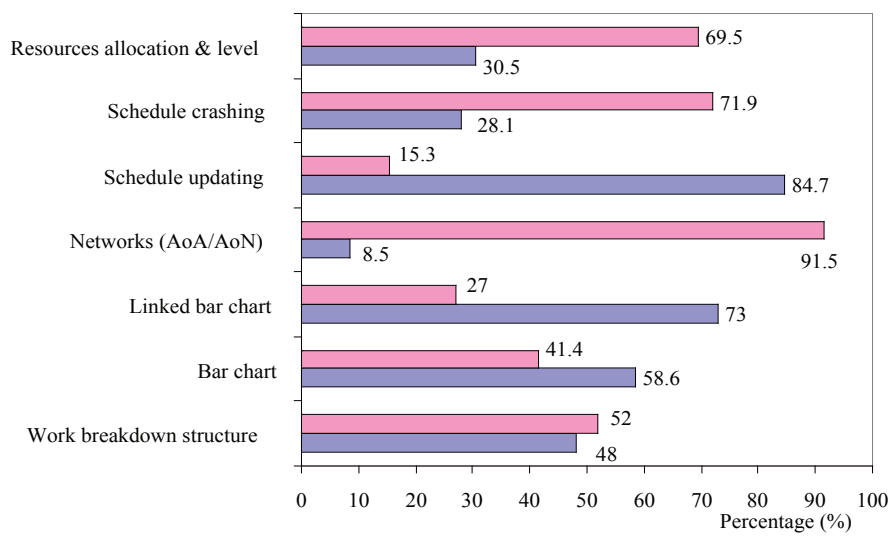

$\square$ Optional

$\square$ Required

Figure 4: Necessity of time tools (contractors' perspective)

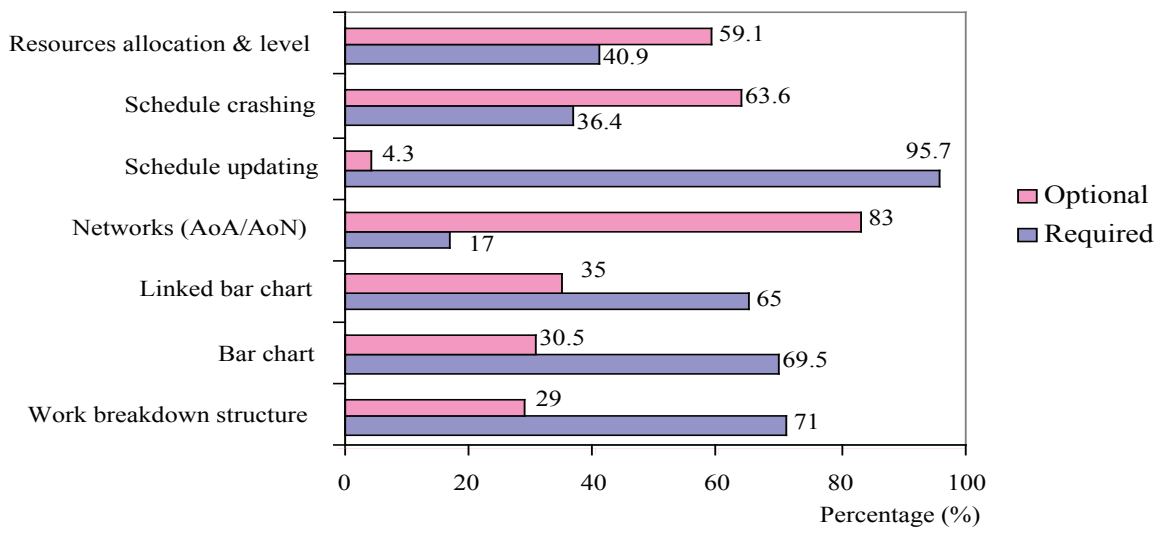

Figure 5: Necessity of time tools (owners' perspective)

\section{OBSTACLES TOWARDS NON-EFFICIENT UTILISATION OF PMTT}

Owners identified "lack of well trained employees" as the most significant obstacle to the non-efficient utilisation of project management tools and techniques (Table 5), while contractors considered "lack of subcontractors knowledge" to be the top obstacle. However, owners regarded this factor as the fourth priority. The difference in rating indicates a different perception in judging the obstacles by both parties since owners have no direct working relationships with subcontractors. With the extensive use of subcontracts on Gaza Strip projects, the contractor respondents appear to blame subcontractor lack of knowledge as the main obstacle. The argument is that most contracting organisations are heavily dependent on the subcontracting approach in executing their projects. Training subcontractors is an important issue for better utilisation of project management tools and techniques. The contractors' union, in the absence of a regulatory body for subcontractors, is held responsible for maintaining and improving subcontractor performance. Furthermore, owners considered 'lack of consultants knowledge on applying PMTT' to be the second most important issue, while contractors regarded it to be the third. Owners considered "employees resistance to change" to be lowest priority, while contractors reported 'lack of top management commitment' to be the lowest priority. 


\begin{tabular}{|l|c|c|c|c|}
\hline \multirow{2}{*}{\multicolumn{1}{|c|}{ Factor }} & \multicolumn{2}{c|}{ Owners } & \multicolumn{2}{c|}{ Contractors } \\
\cline { 2 - 6 } & Freq. & Rank & Freq. & Rank \\
\hline Lack of well trained employees & 70 & 1 & 42 & 4 \\
\hline Unawareness of the importance of PMTT & 57 & 3 & 60 & 2 \\
\hline Lack of consultant capable of helping applying PMTT & 57 & 3 & 42 & 4 \\
\hline Lack of subcontractors' knowledge & 52 & 4 & 65 & 1 \\
\hline Lack of top management commitment & 44 & 5 & 13 & 8 \\
\hline Increasing the cost of implementation & 35 & 6 & 25 & 6 \\
\hline Inadequate knowledge of PMTT & 35 & 7 & 30 & 5 \\
\hline Employee resistance to change & 31 & 8 & 20 & 7 \\
\hline
\end{tabular}

Table 5: Ranking of obstacles to non-efficient utilisation of PMTT

There are significant differences in the lack of top management commitment (Table 6) at Pv $=0.003$, between owners and contractors. A total of $57 \%$ of owners and $87 \%$ of contractors did not believe that 'lack of top management commitment' is an obstacle. This may imply that most of the contractor representatives in the survey were from the top management of the companies, so it was difficult for them to blame top management commitment.

\begin{tabular}{|c|c|c|c|c|c|c|c|c|}
\hline \multirow{3}{*}{\multicolumn{2}{|c|}{ Obstacles }} & \multicolumn{6}{|c|}{ Organisation } & \multirow[t]{3}{*}{ Pv } \\
\hline & & \multirow{2}{*}{$\frac{\text { Contractor }}{\text { No. }}$} & \multirow[b]{2}{*}{$\%$} & \multirow{2}{*}{$\begin{array}{c}\text { Owner } \\
\text { No. } \\
\end{array}$} & \multirow[b]{2}{*}{$\%$} & \multirow{2}{*}{$\begin{array}{l}\text { Total } \\
\text { No. }\end{array}$} & \multirow[b]{2}{*}{$\%$} & \\
\hline & & & & & & & & \\
\hline \multirow{2}{*}{$\begin{array}{l}\text { Lack of top management } \\
\text { commitment }\end{array}$} & Yes & 8 & 13 & 10 & 44 & 18 & 22 & \multirow[t]{2}{*}{$0.003^{\prime}$} \\
\hline & No & 52 & 87 & 13 & 57 & 65 & 78 & \\
\hline \multirow{2}{*}{$\begin{array}{l}\text { Lack of well trained employees } \\
\text { on PMTT }\end{array}$} & Yes & 25 & 42 & 14 & 61 & 39 & 47 & \multirow[t]{2}{*}{0.117} \\
\hline & No & 35 & 58 & 9 & 39 & 44 & 53 & \\
\hline \multirow{2}{*}{$\begin{array}{l}\text { Increasing the cost of } \\
\text { implementation }\end{array}$} & Yes & 15 & 25 & 8 & 35 & 23 & 28 & \multirow[t]{2}{*}{0.373} \\
\hline & No & 45 & 75 & 15 & 65 & 60 & 72 & \\
\hline
\end{tabular}

*Statistically significant

Table 6: Relationship between type of organisation and obstacles o non-efficient implementation of PMTT

On the other hand, more than half of the contractors (59\%) did not agree that 'lack of well trained employees' could represent an obstacle, while $61 \%$ of the owners supported the opposite. The statistical test revealed no significant differences ( $P v=0.117)$. The second highest obstacle was 'unawareness of importance of PMTT'. While owners supported the non-existence of well-trained employees to be the most essential obstacle, they ranked "training program provision" to be the ninth out of ten factors responsible for the successful implementation of PMTT. This can be interpreted that owners are not inclined to train employees although they recognise that the "non- existence of well trained employees" is a major obstacle. They appear to regard training as another party's responsibility. The owners should be leaders for others in improving the level of employee knowledge and skills by continuous training.

The majority of both groups agreed that increasing the cost of implementation' is not an obstacle with preference to contractors $(75 \%)$. The results indicate that there was no statistical significance by type of organisation with this factor $(\mathrm{Pv}=0.373)$.

\section{CONCLUSION}

There are methods that will facilitate efficient project performance. Project time management practices have proven to be an efficient approach, which would help owners and contractors in developing countries in upgrading their management capabilities and enable them to efficiently complete the construction projects and attain development goals. The Gaza Strip is expected to undergo a significant growth where strategic projects will require better understanding of time management tools and techniques.

The use of time management tools and techniques in the construction industry was studied in this research. It can be stated that there is consensus between owners and contractors regarding the application of management tools that the most used time scheduling tool is the linked bar charts, while the least used tool is network scheduling $(\mathrm{AoA} / \mathrm{AoN})$. On the other hand, the results confirm that the work breakdown structure and resources allocation and levelling are not satisfactorily used. The results revealed that there are no significant differences in using time tools between owners and contractors. The findings show that using time tools is generally below a satisfactory level. 
The obstacles that cause non-efficient use of project management practices were investigated. The most essential obstacles reported by owners are lack of well trained employees, unawareness of the importance of PMTT and lack of local experienced consultants who are able to help in applying PMTT. The contractors have regarded the lack of subcontractor's knowledge and skills to be the most conspicuous barrier in addition to what owners believe.

The Palestinian contractors union, engineering syndicates, and continuous education programs should focus more in conducting training courses and seminars for local engineers in order to improve the usage of project management tools and to overcome the identified obstacles towards the non-efficient applications of time management tools. The training courses should be tailored to improve the abilities of using work breakdown structure, resource optimisation, network scheduling, parametric estimating, cost variance analysis, and earned value concepts.

The implementation of project management tools and techniques is not seriously considered in the construction industry in the Gaza Strip. Therefore, it is crucial to both owners and construction contractors to take practical measures to benefit from the application of the management tools and techniques. This study recommends that there is an urgent need to establish a professional industry body such as an Institute of Building to review and evaluate existing local project management practices. This professional body may be conducted by the government through the Ministry of Housing and Public Works or by the local university in cooperation with similar international professional industry bodies. Further study is recommended to investigate the relationship between the effectiveness of project management tools and cost benefits and effectiveness.

\section{REFERENCES}

Abbasi, G. and Al-Mharmah, H. (2000), 'Project management by the public sector in a developing country', International Journal of Project Management, vol.18, no.2, pp.105-109.

Enshassi, A. (1997), 'Site organization and supervision in housing project in the Gaza Strip', International Journal of Project Management, vol.15, no.2, pp.93-99.

FAFO Report (1993), Palestine Society.

Hutchings, D.M. and Christofferson, J.P. (2000), 'A study of management practices in small-volume home building companies', in proceedings of the ASC 36th Annual Conference, Purdue University, Indiana, pp.211-220.

Hutchings, D.M. and Christofferson, J.P. (2001), 'Management practices of residential construction companies producing 25 and fewer annually', in proceedings of the ASC 37th Annual Conference, University of Denver, Colorado, pp.115-121.

Kazi, A.S. (2002), Project planning and control parameter analysis, mail questionnaire.

MAS (2001), Economic monitoring report, Palestinian Economic Policy Research Institute, (www.palecon.org/masdir/monitor/ monitor.html).

Mezher, T. and Tawil, W. (1998), 'Causes of delays in the construction industry in Lebanon', Engineering Construction and Architectural Management Journal, vol.5, no.3, pp.251-260.
PECDAR (1997), Housing in Palestine, (www.pecdar.org).

PCBS (2000), Number of enterprises and persons engaged for construction contractors (1995-1999), the Palestinian Central Bureau of Statistics, (www.pcbs.org).

Shash A. and Al-abdullatif A.M. (1993), 'A survey of planning and controlling techniques used by construction contractors in Saudi Arabia', Cost Engineering, vol.35, no.2, pp.95-112.

White, D. and Fortune, J. (2002), 'Current practice in project management - an imperial study', International Journal of Project Management, vol.20, no.3.

World Bank (2001), West Bank and Gaza in brief, (www. worldbank.org).

Yang, M.L., Chuah, K.B., Rao Tummala, V.M. and Chen, E.H. (1997), 'Project management practices in Pudong', International Journal of Project Management, vol.15, no.5, pp.313-319. 